CrossMark

\&click for updates

Cite this: Catal. Sci. Technol., 2015, 5,2305

\title{
Catalytic oxidation of formaldehyde over manganese oxides with different crystal structures $\uparrow$
}

\author{
Jianghao Zhang, Yaobin Li, Lian Wang, Changbin Zhang* and Hong He
}

$\alpha-, \beta-, \gamma-$ and $\delta-\mathrm{MnO}_{2}$ catalysts were prepared by a hydrothermal method and tested for the catalytic oxidation of formaldehyde $(\mathrm{HCHO})$ at low temperature. Dramatic differences in activities among the $\mathrm{MnO}_{2}$ catalysts with different crystal structures were observed. The $\delta-\mathrm{MnO}_{2}$ catalyst exhibited the best activity among the four catalysts and achieved nearly complete $\mathrm{HCHO}$ conversion at $80{ }^{\circ} \mathrm{C}$, while the $\alpha-, \beta-$ and $\gamma$-type $\mathrm{MnO}_{2}$ obtained $100 \% \mathrm{HCHO}$ conversion at $125^{\circ} \mathrm{C}, 200^{\circ} \mathrm{C}, 150{ }^{\circ} \mathrm{C}$, respectively. The catalysts were next characterized by Brunauer-Emmett-Teller (BET), X-ray diffraction (XRD), Field-Emission Scanning Electron Microscopy (FE-SEM), temperature-programmed reduction by $\mathrm{H}_{2}\left(\mathrm{H}_{2}\right.$-TPR), $\mathrm{X}$-ray photoelectron spectroscopy (XPS) and temperature-programmed desorption of $\mathrm{HCHO}$ ( $\mathrm{HCHO}-\mathrm{TPD})$ methods to investigate the factors influencing the catalytic activity. Based on the characterization results, it is supposed that the tunnel structure and active lattice oxygen species are the main factors that contribute to the excellent performance of $\delta-\mathrm{MnO}_{2}$. According to the high catalytic performance and facile preparation process, $\delta-\mathrm{MnO}_{2}$ may potentially be used as a support in applications of supported catalysts.

Received 7th November 2014 Accepted 17th January 2015

DOI: $10.1039 / \mathrm{c} 4 \mathrm{cy} 01461 \mathrm{~h}$

www.rsc.org/catalysis capacity and the hazard of desorption during regeneration. The catalytic oxidation method spurns the above drawbacks and could selectively decompose low concentration toxic $\mathrm{HCHO}$ to harmless $\mathrm{CO}_{2}$ and $\mathrm{H}_{2} \mathrm{O}$ even at ambient temperature. It has been shown to be a promising method for indoor air HCHO removal. ${ }^{12}$

There are two main kinds of catalysts for HCHO oxidation including supported noble metal ( $\mathrm{Pt}, \mathrm{Au}, \mathrm{Rh}$ and $\mathrm{Pd})^{13-18}$ and non-noble metal oxide ( $\mathrm{Ag}$, Co, Ce and $\mathrm{Mn})^{10,19-24}$ catalysts. The supported noble metal catalysts such as alkali-metaldoped $\mathrm{Na}-\mathrm{Pt} / \mathrm{TiO}_{2},{ }^{9,25} \mathrm{Pt} / \mathrm{MnO}_{x}-\mathrm{CeO}_{2},{ }^{16} \mathrm{TiO}_{2}$ supported $\mathrm{Pd}$ nanoparticles, ${ }^{17}$ and Na-promoted $\mathrm{Pd} / \mathrm{TiO}_{2},{ }^{18}$ have shown remarkable catalytic activities at ambient temperature even at high space velocity. However, the high price inhibited their wide application. In contrast, the transition metal oxides are much cheaper; some catalysts have also proven to be effective for low temperature HCHO oxidation. Therefore, the transition metal oxides are regarded as promising alternative catalysts to noble metal catalysts.

Mn based catalysts have been widely studied for HCHO oxidation and appear to be the most active catalysts among the transition metal oxides. It was reported that the preparation method, morphology, tunnel structures, etc., have considerable influence on the catalytic activity of $\mathrm{Mn}$ based catalysts. Tang et al. reported that $\mathrm{MnO}_{x}-\mathrm{CeO}_{2}$ prepared by a modified co-precipitation method showed a better performance than those prepared with sol-gel or co-precipitation methods, achieving complete $\mathrm{HCHO}$ conversion at $373 \mathrm{~K}^{26}$ 
Chen et al. found that $\mathrm{MnO}_{x}$ with a hollow nanostructure had a much higher activity than that with a honeycomb nanostructure. ${ }^{27}$ Chen et al. studied the tunnel structure effect on Mn oxide activity and suggested that the $[2 \times 2]$ tunnel structure could dramatically elevate the catalytic activity of Mn oxides. ${ }^{28}$ Wang et al. observed that the 3D ordered cubic mesoporous Co-Mn oxide is a highly effective catalyst for HCHO oxidation and obtained the complete oxidation of $\mathrm{HCHO}$ at $70{ }^{\circ} \mathrm{C}^{29}$

In this study, $\mathrm{MnO}_{2}$ catalysts with $\alpha-, \beta-, \gamma$ - and $\delta$-phase structures were prepared by a hydrothermal process and then tested for their performance in the catalytic oxidation of formaldehyde ( $\mathrm{HCHO}$ ) at low temperature. A dramatic difference in the catalytic activity was clearly observed between the four kinds of $\mathrm{MnO}_{2} \cdot \delta-\mathrm{MnO}_{2}$ showed the best catalytic activity of the four materials, achieving almost $100 \%$ conversion of $170 \mathrm{ppm} \mathrm{HCHO}$ at $80{ }^{\circ} \mathrm{C}$ with a gas hourly space velocity of $100000 \mathrm{~mL}\left(\mathrm{~g}_{\text {cat }} \mathrm{h}\right)^{-1}$. The catalysts were carefully characterized by XRD, BET, FE-SEM, $\mathrm{H}_{2}$-TPR, XPS and HCHO-TPD measurements. Based on the results, the factors affecting the catalytic activity were elucidated.

\section{Experimental section}

\subsection{Preparation of catalysts}

The four kinds of manganese oxide with different phase structures were prepared by a hydrothermal method according to the previous report. ${ }^{30}$ For the $\alpha-\mathrm{MnO}_{2}, 0.525 \mathrm{~g}$ $\mathrm{MnSO}_{4} \cdot \mathrm{H}_{2} \mathrm{O}$ and $1.25 \mathrm{~g} \mathrm{KMnO}_{4}$ were mixed in $80 \mathrm{~mL}$ distilled water, then stirred magnetically for about $30 \mathrm{~min}$ to form a homogeneous solution before it was moved into a Teflonlined stainless steel autoclave $(100 \mathrm{~mL})$. After that, the autoclave was heated to $160{ }^{\circ} \mathrm{C}$ for $12 \mathrm{~h}$ in an oven. The product was collected, washed, filtered, dried at $80{ }^{\circ} \mathrm{C}$ and then calcined at $300{ }^{\circ} \mathrm{C}$. The procedures for the preparation of other manganese oxides were similar to that of $\alpha-\mathrm{MnO}_{2}$ except for the precursor, the reaction temperature and the reaction duration.

For $\beta-\mathrm{MnO}_{2}, 1.69 \mathrm{~g} \mathrm{MnSO}_{4} \cdot \mathrm{H}_{2} \mathrm{O}$ and $2.28 \mathrm{~g}\left(\mathrm{NH}_{4}\right)_{2} \mathrm{~S}_{2} \mathrm{O}_{8}$ reacted at $140{ }^{\circ} \mathrm{C}$ for $12 \mathrm{~h}$.

For $\gamma-\mathrm{MnO}_{2}, 3.375 \mathrm{~g} \mathrm{MnSO}_{4} \cdot \mathrm{H}_{2} \mathrm{O}$ and $4.575 \mathrm{~g}\left(\mathrm{NH}_{4}\right)_{2} \mathrm{~S}_{2} \mathrm{O}_{8}$ reacted at $90{ }^{\circ} \mathrm{C}$ for $24 \mathrm{~h}$.

For $\delta-\mathrm{MnO}_{2}, 0.275 \mathrm{~g} \mathrm{MnSO}_{4} \cdot \mathrm{H}_{2} \mathrm{O}$ and $1.5 \mathrm{~g}^{\mathrm{KMnO}_{4}}$ were heated to $240{ }^{\circ} \mathrm{C}$ for $24 \mathrm{~h}$.

\subsection{Characterization}

The structure parameters, pore characterization and specific surface area of the samples were obtained by a BET plot using a Quantachrome Quadrasorb SI-MP at $-196{ }^{\circ} \mathrm{C}$ over the whole range of relative pressures. The pore size distribution was calculated by the desorption branch of the $\mathrm{N}_{2}$ adsorption isotherm using the $\mathrm{BJH}$ method. Before the $\mathrm{N}_{2}$ physisorption, the catalysts were degassed at $300{ }^{\circ} \mathrm{C}$ for $5 \mathrm{~h}$.

XRD patterns were measured on an X'Pert PRO MPD X-ray powder diffractometer with $\mathrm{Cu} \mathrm{K} \alpha$ radiation operated at
$40 \mathrm{kV}$ and $40 \mathrm{~mA}$. The $2 \theta$ angle ranged from $10^{\circ}$ to $80^{\circ}$ with a scan step of $0.02^{\circ}$.

Field-Emission Scanning Electron Microscopy (FE-SEM) images were obtained using an SU-8020 scanning electron microscope. The samples for FE-SEM measurements were prepared by depositing the powder on a conductive tape using $\mathrm{N}_{2}$ vertical purging. The voltage exerted for lower amplification was $3 \mathrm{kV}$ while for higher amplification was $1 \mathrm{kV}$.

Temperature-programmed reduction (TPR) was carried out on a Chemisorption Analyzer (AutoChem 2920) equipped with a TCD detector. After sweeping by Ar and air successively, a flow of $10 \% \mathrm{H}_{2} / \mathrm{Ar}$ at a rate of $50 \mathrm{~cm}^{3} \mathrm{~min}^{-1}$ (STP) passed the samples with the temperature increasing from 100 to $600{ }^{\circ} \mathrm{C}$ at a rate of $10{ }^{\circ} \mathrm{C} \mathrm{min}^{-1}$. The $\mathrm{H}_{2}$ consumption was monitored by TCD after produced $\mathrm{H}_{2} \mathrm{O}$ removal.

X-ray photoelectron spectroscopy (XPS) profiles were obtained by an AXIS Ultra system, equipped with Al K $\alpha$ radiation $(h v=1486.6 \mathrm{eV})$ with an anode operated at $225 \mathrm{~W}$ and $15 \mathrm{kV}$. The binding energy values were calibrated using the $\mathrm{C}$ 1 s peak $(284.8 \mathrm{eV})$. The surface relative composition was estimated from the integrated intensities corrected by atomic sensitivity factors.

The temperature-programmed desorption of $\mathrm{HCHO}$ (HCHO-TPD) measurements on the samples were carried out on a Micromeritics AutoChem II 2920 instrument. The catalysts were loaded in a quartz reactor and heated at $200{ }^{\circ} \mathrm{C}$ for $0.5 \mathrm{~h}$ in the argon flow to remove the absorbed $\mathrm{CO}_{2}$ and $\mathrm{H}_{2} \mathrm{O}$. After being cooled to $-20{ }^{\circ} \mathrm{C}$, the samples were saturated by HCHO-helium mixed gas for $1 \mathrm{~h}$. Then the flow gas was changed to pure helium for $0.5 \mathrm{~h}$, followed by temperature ramping to $250{ }^{\circ} \mathrm{C}$ at a linear rate of $10{ }^{\circ} \mathrm{C} \mathrm{min}-1$. The products $\mathrm{HCHO}$ and $\mathrm{CO}_{2}$ were monitored using a Cirrus II Mass Spectrometer at $m / z$ ratios of 30 and 44 , respectively.

\subsection{Activity test}

The activity tests for the catalytic oxidation of $\mathrm{HCHO}$ over the catalysts $(60 \mathrm{mg})$ were performed in a fixed-bed quartz flow reactor (i.d. $=4 \mathrm{~mm}$ ) in an incubator. Gaseous $\mathrm{HCHO}$ was generated by flowing nitrogen through the paraformaldehyde container in a water bath kept at $35^{\circ} \mathrm{C}$. The feed gas composition was $170 \mathrm{ppm} \mathrm{HCHO}, 20 \% \mathrm{O}_{2}$ and 25\% RH balanced by

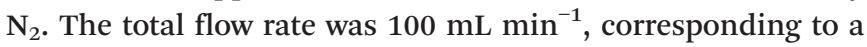
gas hourly space velocity (GHSV) of $100000 \mathrm{~mL}\left(\mathrm{~g}_{\text {cat }} \mathrm{h}\right)^{-1}$. $\delta-\mathrm{MnO}_{2}$ was also tested under a high GHSV of $600000 \mathrm{~mL}$ $\left(g_{\text {cat }} h\right)^{-1}$ to control HCHO conversion below $100 \%$ for the measurement of specific reaction rate.

As with our previous activity evaluating instruments and methods, ${ }^{9,18}$ the inlet and outlet gases were monitored by FTIR spectroscopy (Nicolet iS50) equipped with $2 \mathrm{~m}$ gas cell and a DTGS detector; resolution: $0.5 \mathrm{~cm}^{-1}$; OPD velocity: $0.4747 \mathrm{~cm} \mathrm{~s}^{-1}$. The collection region was $4000-600 \mathrm{~cm}^{-1}$ and the number of scans per spectrum was 16 . $\mathrm{HCHO}$ and $\mathrm{CO}_{2}$ were measured by the peaks located at 2897 (C-H vibration) and $2350 \mathrm{~cm}^{-1}$ (O-C-O vibration), respectively. Since no other 
carbon containing compounds except for $\mathrm{CO}_{2}$ were detected in the effluents for all tested catalysts, the $\mathrm{HCHO}$ and $\mathrm{CO}_{2}$ concentrations were quantified and calculated based on the peak area of $\mathrm{CO}_{2}$ at $2350 \mathrm{~cm}^{-1}$.

The lattice oxygen test experiments were also carried out over $\delta-\mathrm{MnO}_{2}$ to check the role of the lattice oxygen species in the HCHO oxidation reaction. The initial HCHO concentration, catalyst amount and GHSV were the same as the normal activity test experiment. In detail, the procedure is as follows: the samples were first pretreated at $150{ }^{\circ} \mathrm{C}$ for $30 \mathrm{~min}$ in a

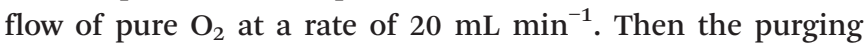
gas was switched to pure $\mathrm{N}_{2}$ at a rate of $100 \mathrm{~mL} \mathrm{~min}{ }^{-1}$ for $30 \mathrm{~min}$ to remove gaseous $\mathrm{O}_{2}$ and the weakly absorbed oxygen species. After that, the temperature was lowered to $X{ }^{\circ} \mathrm{C}(X=$ $50,75)$ and then the $\mathrm{HCHO}$ balanced with $\mathrm{N}_{2}$ was introduced into the reactor and the products were monitored by FTIR spectroscopy.

\section{Results and discussion}

\subsection{Crystal structure and morphology of catalyst}

XRD patterns were measured to investigate the crystallographic structures of the samples and the results are shown in Fig. 1. All of the four samples could be well indexed and were in good agreement with the lattice constants of $\alpha-\mathrm{MnO}_{2}$ (JCPDS 44-0141), $\beta-\mathrm{MnO}_{2}$ (JCPDS 24-0735), $\gamma-\mathrm{MnO}_{2}$ (JCPDS 14-0644) and $\delta-\mathrm{MnO}_{2}$ (JCPDS 80-1098), confirming the successful preparation of $\mathrm{MnO}_{2}$ with four types of crystal structures, which were also verified by the Raman spectra and lattice distances measured by high-resolution transmission electron microscopy (HR-TEM) (ESI, $\dagger$ Fig. S1 and S2). In addition, it could be inferred that $\alpha-\mathrm{MnO}_{2}$ and $\beta-\mathrm{MnO}_{2}$ had high crystallinity according to their narrow peak widths and high intensities. In contrast, $\gamma-\mathrm{MnO}_{2}$ presented a very poor XRD pattern. As reported, $\gamma-\mathrm{MnO}_{2}$ is normally the product of irregular intergrowth of elements of ramsdellite and pyrolusite ${ }^{31,32}$ thus no complete single crystal will emerge in the structure, leading to the low crystallinity of $\gamma-\mathrm{MnO}_{2} . \delta-\mathrm{MnO}_{2}$

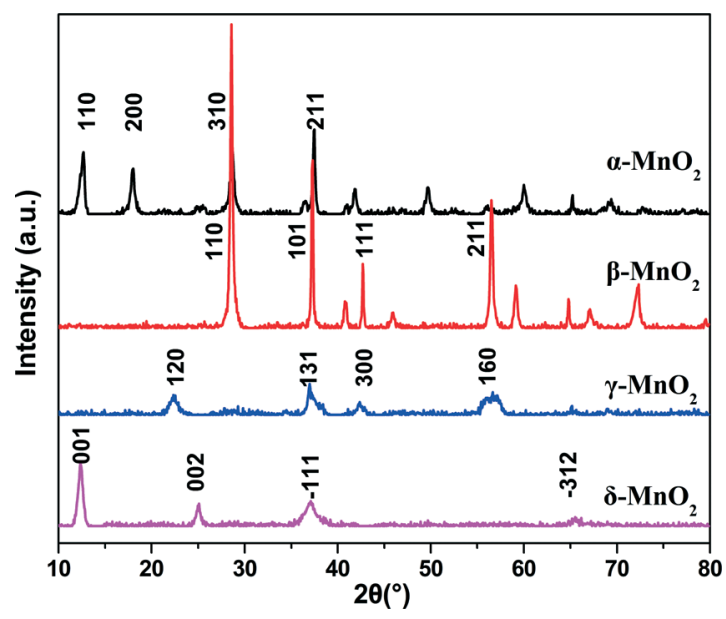

Fig. 1 XRD patterns of $\alpha-, \beta-, \gamma-$ and $\delta-\mathrm{MnO}_{2}$ samples. generally has the disordered structures in certain crystallographic directions. ${ }^{33}$ Therefore, $\delta-\mathrm{MnO}_{2}$ showed much broader and weaker XRD peaks than those of $\alpha-\mathrm{MnO}_{2}$ and $\beta-\mathrm{MnO}_{2}$.

Table 1 shows the specific surface areas $\left(S_{\mathrm{BET}}\right)$, average pore sizes $(d)$, and total pore volumes $(V)$ of the four samples. $\delta-\mathrm{MnO}_{2}$ showed the highest $S_{\mathrm{BET}}$, average pore size $(d)$ and $V$ among the four catalysts. The $\alpha$ - and $\gamma-\mathrm{MnO}_{2}$ samples exhibited much similar moderate values of $S_{\mathrm{BET}}, d$ and $V$. In contrast, $\beta-\mathrm{MnO}_{2}$ presented the lowest parameters.

FE-SEM images of the $\alpha-, \beta-, \gamma$ - and $\delta-\mathrm{MnO}_{2}$ samples (two magnifications for each) are shown in Fig. 2. $\alpha-\mathrm{MnO}_{2}$ showed a dendritic nanostructure (Fig. 2a) which was composed of uniform nanorods; the size of each individual nanorod is about $2.5 \mu \mathrm{m}$ long and $30 \mathrm{~nm}$ wide. $\beta-\mathrm{MnO}_{2}$ had similar dendritic nanostructures (Fig. 2b) which consisted of tetragonal prism nanorods, $2 \mu \mathrm{m}$ long and 50-100 nm wide. $\gamma-\mathrm{MnO}_{2}$ displayed a spherical nanostructure which was composed of $\mathrm{MnO}_{2}$ nanoneedles with sharp tips. The $\gamma-\mathrm{MnO}_{2}$ nanoneedles had lengths of about $2.5 \mu \mathrm{m}$ and diameters of about $40 \mathrm{~nm}$. $\delta-\mathrm{MnO}_{2}$ also had a spherical morphology with a diameter of 2-3 $\mu \mathrm{m}$, which was built up of many interleaving nanoflakes composed of very thin nanowires with widths of 10-20 nm. The morphology of the samples was also surveyed by HRTEM (ESI, $\uparrow$ Fig. S2), which showed consistent results with the SEM images.

\subsection{Activity test}

Fig. 3 shows the $\mathrm{HCHO}$ conversion to $\mathrm{CO}_{2}$ as a function of temperature over the $\alpha-\beta-, \gamma$ - and $\delta-\mathrm{MnO}_{2}$ catalysts at a GHSV of $100000 \mathrm{~mL}\left(\mathrm{~g}_{\text {cat }} \mathrm{h}\right)^{-1}$ with an inlet HCHO concentration of $170 \mathrm{ppm}$. The temperature dependence of the HCHO conversions were distinctly related to the phase structures of $\mathrm{MnO}_{2}$. The catalytic activities followed the sequence $\delta->\alpha-$ $>\gamma->\beta-\mathrm{MnO}_{2} \cdot \delta-\mathrm{MnO}_{2}$ showed the best catalytic activity among the four samples and $100 \%$ HCHO conversion was obtained at around $80{ }^{\circ} \mathrm{C}$. The other catalysts $\alpha-, \beta$ - and $\gamma-\mathrm{MnO}_{2}$ exhibited a much lower activity than $\delta-\mathrm{MnO}_{2}$ with $100 \%$ HCHO conversions achieved at $125{ }^{\circ} \mathrm{C}, 200{ }^{\circ} \mathrm{C}$, and $150{ }^{\circ} \mathrm{C}$, respectively. The above findings clearly showed that the catalytic activity of $\mathrm{MnO}_{2}$ for the oxidation of $\mathrm{HCHO}$ was in tight correlation with the crystal structures. In order to eliminate the influence of surface area, the specific reaction rate $\left(R_{\mathrm{S}}\right)$ at $100{ }^{\circ} \mathrm{C}$ in terms of the generated amount of $\mathrm{CO}_{2}$ per

Table 1 Specific surface area $\left(S_{\mathrm{BET}}\right)$, average pore size $(d)$, total pore volume $(V)$ and normalized reaction rate $\left(R_{\mathrm{s}}\right)$ of the $\alpha-, \beta-, \gamma-$ and $\delta-\mathrm{MnO}_{2}$ catalysts

\begin{tabular}{lllll}
\hline Samples & $\begin{array}{l}S_{\mathrm{BET}} \\
{\left[\mathrm{m}^{2} \mathrm{~g}^{-1}\right]}\end{array}$ & $\begin{array}{l}\text { Pore diameter } \\
(d)[\mathrm{nm}]\end{array}$ & $\begin{array}{l}\text { Pore volume }(V) \\
{\left[\mathrm{cm}^{3} \mathrm{~g}^{-1}\right]}\end{array}$ & $\begin{array}{l}R_{\mathrm{s}}[\mathrm{nmol} \\
\left.\mathrm{s}^{-1} \mathrm{~m}^{-2}\right]\end{array}$ \\
\hline$\alpha-\mathrm{MnO}_{2}$ & 80.8 & 13.2 & 0.27 & 1.87 \\
$\beta-\mathrm{MnO}_{2}$ & 23.3 & 11.4 & 0.05 & 0.63 \\
$\gamma-\mathrm{MnO}_{2}$ & 85.3 & 12.2 & 0.26 & 0.44 \\
$\delta-\mathrm{MnO}_{2}$ & 108.4 & 14.1 & 0.38 & 9.42
\end{tabular}



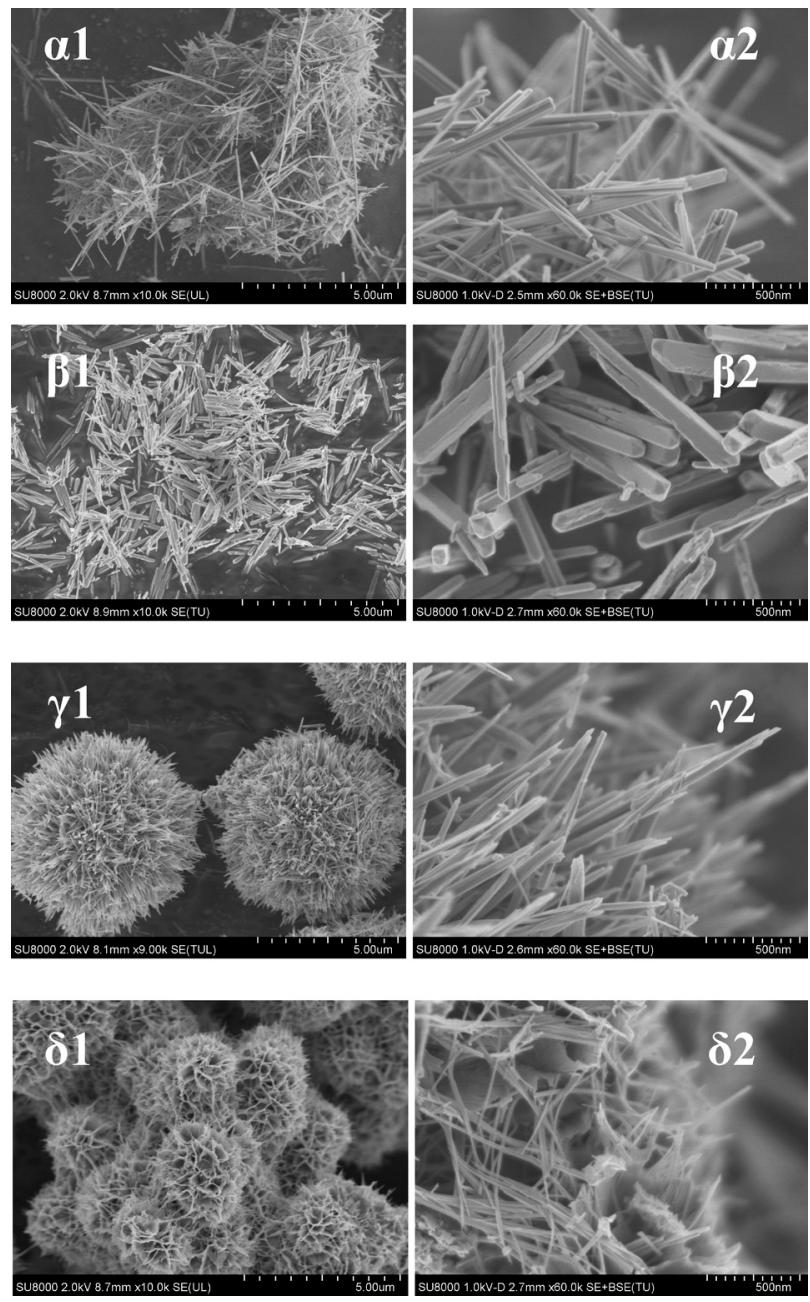

Fig. 2 SEM images of the $\alpha-, \beta-, \gamma-$ and $\delta-\mathrm{MnO}_{2}$ samples, 1 and 2 refer to different magnifications of one sample.

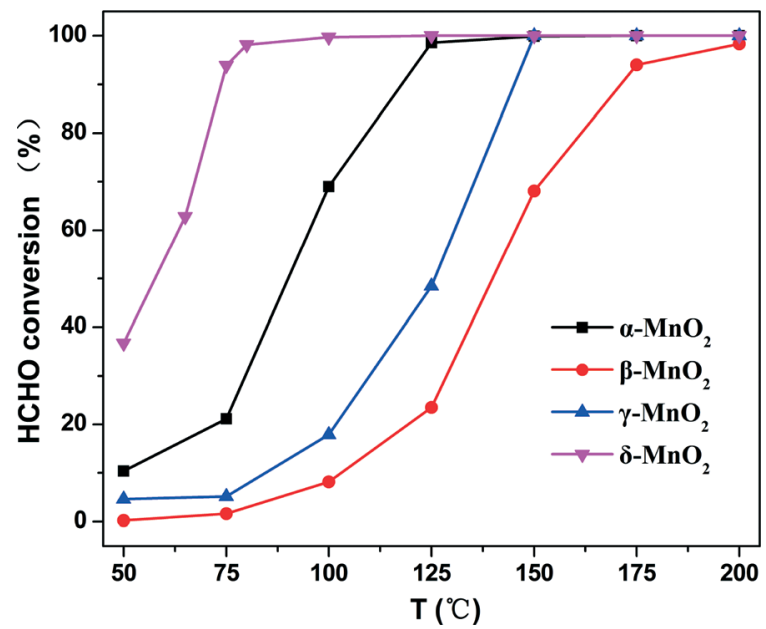

Fig. $3 \mathrm{HCHO}$ conversions over $\alpha-, \beta-, \gamma-$ and $\delta-\mathrm{MnO}_{2}$ samples. Reaction conditions: $170 \mathrm{ppm}$ of $\mathrm{HCHO}, 20 \% \mathrm{O}_{2}, \mathrm{~N}_{2}$ balance, GHSV = $100000 \mathrm{~mL}\left(\mathrm{~g}_{\mathrm{cat}} \mathrm{h}\right)^{-1}$. unit area is calculated and given in Table 1 . For the $R_{\mathrm{S}}$ measurement, $\delta-\mathrm{MnO}_{2}$ was tested under a high GHSV of 600000 $\mathrm{mL}\left(\mathrm{g}_{\text {cat }} \mathrm{h}\right)^{-1}$ with a conversion of $80.5 \%$ at $100{ }^{\circ} \mathrm{C}$. As shown in Table 1, the $R_{\mathrm{s}}$ of $\delta-\mathrm{MnO}_{2}$ is $9.42 \mathrm{nmol} \mathrm{s} \mathrm{m}^{-1} \mathrm{~m}^{-2}$, which is much higher (around 5 times that of the second best) than the other catalysts. These results indicate that the oxidation of $\mathrm{HCHO}$ is drastically enhanced on the $\delta$ - $\mathrm{MnO}_{2}$ catalysts, implying $\delta-\mathrm{MnO}_{2}$ could be a potential catalyst for $\mathrm{HCHO}$ oxidation. Liang et $a l^{30}$ have tested the catalytic properties of $\alpha-, \beta-, \gamma-$ and $\delta-\mathrm{MnO}_{2}$ catalysts for $\mathrm{CO}$ oxidation. They observed that the catalytic activities decreased in the order $\alpha-\approx \delta->\gamma->\beta-\mathrm{MnO}_{2}$ and the $\alpha-\mathrm{MnO}_{2}$ catalyst had a similar activity to $\delta-\mathrm{MnO}_{2}$. However, in this study, the series of catalysts showed a different catalytic behaviour for HCHO oxidation and $\delta-\mathrm{MnO}_{2}$ was much more active than $\alpha-\mathrm{MnO}_{2}$. Therefore, the key factor affecting the activity of the $\mathrm{MnO}_{2}$ catalysts should be different for these two reactions.

The stability of the $\delta-\mathrm{MnO}_{2}$ catalyst was checked by long isothermal tests at $75{ }^{\circ} \mathrm{C}$ with a GHSV of $150000 \mathrm{~mL}$ $\left(\mathrm{g}_{\text {cat }} \mathrm{h}\right)^{-1}$. As shown in Fig. 4 , in the beginning, there is a certain rise of the conversion rate which might be due to some highly active and non-renewable adsorbed oxygen species. The rate then dropped and stabilized at around $60 \%$. Overall, the sample exhibited excellent stability and efficiency, and the approximately $60 \%$ HCHO conversion rate was maintained over a $30 \mathrm{~h}$-long test. After the reaction and stability tests, the XRD patterns of the four catalysts were also measured, and the results showed that their crystalline structures remained intact (ESI,† Fig. S3).

\subsection{Effect of $\mathrm{K}^{+}$}

There are several factors that might influence the activity of manganese oxides. Hou et al. ${ }^{34}$ have reported that increasing the $\mathrm{K}^{+}$content would drastically enhance the catalytic activity of OMS-2 catalysts for the catalytic oxidation of benzene.

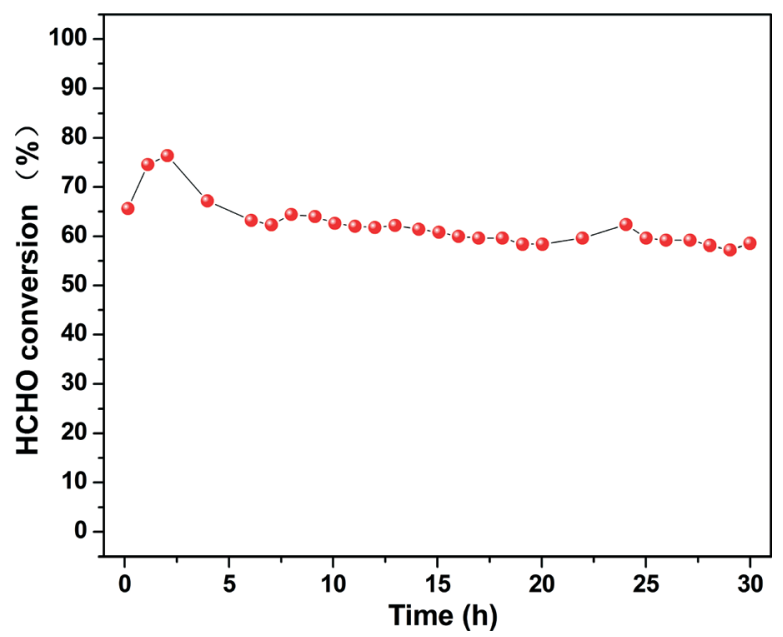

Fig. 4 Stability test of the $\delta-\mathrm{MnO}_{2}$ catalyst in terms of the production amount of $\mathrm{CO}_{2}$. Reaction conditions: $75{ }^{\circ} \mathrm{C}, 170 \mathrm{ppm}$ of $\mathrm{HCHO}, 20 \%$ $\mathrm{O}_{2}, \mathrm{~N}_{2}$ balance, GHSV $=150000 \mathrm{~mL}\left(\mathrm{~g}_{\text {cat }} \mathrm{h}\right)^{-1}$. 
Therefore, we first investigated the possible effect of the $\mathrm{K}^{+}$ species on the catalytic activity of the series of $\mathrm{MnO}_{2}$ catalysts for HCHO oxidation. ICP-OES was carried out to measure the $\mathrm{K}^{+}$content in the four catalysts and the quantitative results are summarized in Table 2 . The $\mathrm{K}^{+}$volume in $\alpha-\mathrm{MnO}_{2}$ and $\delta-\mathrm{MnO}_{2}$ was $7.1 \mathrm{wt} . \%$ and $6.4 \mathrm{wt} . \%$, respectively, and no $\mathrm{K}^{+}$ was detected in the $\beta$ - and $\gamma-\mathrm{MnO}_{2}$ catalysts. The amount of $\mathrm{K}^{+}$in $\alpha-\mathrm{MnO}_{2}(7.1 \mathrm{wt} . \%)$ was slightly higher than that in $\delta-\mathrm{MnO}_{2}$ (6.4 wt.\%), however, $\alpha-\mathrm{MnO}_{2}$ showed a much lower activity for $\mathrm{HCHO}$ oxidation than $\delta-\mathrm{MnO}_{2}$, indicating that the $\mathrm{K}^{+}$presence was not the reason for the activity difference between these two catalysts. $\alpha-\mathrm{MnO}_{2}$ without $\mathrm{K}^{+}$species was next prepared following the procedures reported by $\mathrm{Hou}$ et $a .^{34}$ and then tested under the same conditions as the normal activity test. An activity comparison of the two kinds of $\alpha-\mathrm{MnO}_{2}$ sample as well as the $\gamma-\mathrm{MnO}_{2}$ sample is shown in Fig. 5. It is indicated that the activity of $\alpha-\mathrm{MnO}_{2}$ slightly dropped in the absence of $\mathrm{K}^{+}$species, but is still much higher than $\gamma-\mathrm{MnO}_{2}$. Thus, it could be concluded that the $\mathrm{K}^{+}$species was not the main factor affecting the activities of the four types of $\mathrm{MnO}_{2}$ catalyst for $\mathrm{HCHO}$ oxidation.

\subsection{Tunnel structure}

As reported, the four kinds of $\mathrm{MnO}_{2}$ catalyst contain different types of tunnel structures. ${ }^{35} \alpha-\mathrm{MnO}_{2}$ consists of $[2 \times 2]$ and $[1 \times 1]$ tunnel structures. $\beta-\mathrm{MnO}_{2}$ is composed of a $[1 \times 1]$ tunnel structure. $\gamma-\mathrm{MnO}_{2}$ contains both $[1 \times 1]$ and $[1 \times 2]$ tunnels. In contrast, $\delta-\mathrm{MnO}_{2}$ forms a $2 \mathrm{D}$ layer structure. Therefore, the distinction in activities between the $\mathrm{MnO}_{2}$ catalysts might be partially ascribed to the different tunnel structures. Liang et $a .^{30}$ have reported that the tunnel structure could affect the CO chemisorption, therefore obviously influence the catalytic activity of $\mathrm{MnO}_{2}$ for $\mathrm{CO}$ oxidation. In addition, Chen et al. $^{28}$ have observed that $\mathrm{MnO}_{2}$ with the $[2 \times 2]$ tunnel structure is much more active than $\mathrm{MnO}_{2}$ with the $[1 \times 1]$ or $[3 \times 3]$ structure for $\mathrm{HCHO}$ oxidation since the effective diameter of the $[2 \times 2]$ tunnel is more suitable for the HCHO diffusion during the reaction. Our results were consistent with the reported result in that $\alpha$ - was more active than $\beta$ - and $\gamma$-. Moreover, the present results also suggested that the interlayer structure of $\mathrm{MnO}_{2}$ would benefit the $\mathrm{HCHO}$ oxidation reaction more than the $[2 \times 2]$ tunnel structure by facilitating the absorption and diffusion of $\mathrm{HCHO}$ molecules to active sites. Therefore, the different tunnel structure among $\alpha-, \beta-$,

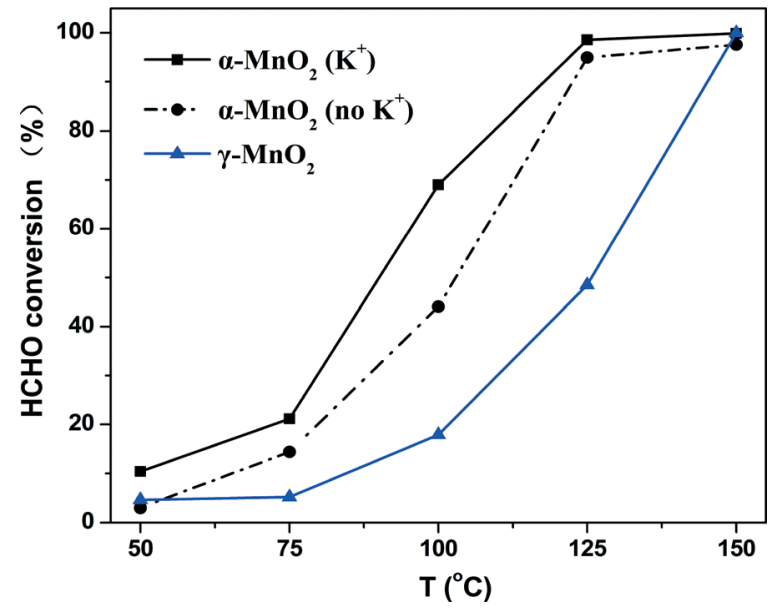

Fig. 5 Activity test of the three samples: $\alpha$ - with/without $\mathrm{K}^{+}$and $\gamma-\mathrm{MnO}_{2}$. Reaction conditions: $170 \mathrm{ppm}$ of $\mathrm{HCHO}, 20 \% \mathrm{O}_{2}, \mathrm{~N}_{2}$ balance, GHSV $=100000 \mathrm{~mL}\left(g_{\text {cat }} h\right)^{-1}$

$\gamma$ - and $\delta-\mathrm{MnO}_{2}$ catalysts should be one of the reasons for their different activities.

\subsection{Reducibility of catalyst}

$\mathrm{H}_{2}$-TPR experiments were next performed to investigate the reducibility of the four samples. Fig. 6 shows the $\mathrm{H}_{2}$-TPR profiles of the $\alpha-, \beta-, \gamma$ - and $\delta-\mathrm{MnO}_{2}$ catalysts. $\beta-\mathrm{MnO}_{2}$ presented a sharp peak at $301{ }^{\circ} \mathrm{C}$ with a broad peak at $419{ }^{\circ} \mathrm{C}$. Accounting for the peak area which could indicate the hydrogen consumption amount, the ratio of the lower temperature peak to the higher one is about $2: 1$. This is a typical feature of the reduction of $\mathrm{MnO}_{2}$, consistent with conversion of $\mathrm{MnO}_{2}$ to $\mathrm{Mn}_{3} \mathrm{O}_{4}$, which leads to the lower temperature peak, and then $\mathrm{Mn}_{3} \mathrm{O}_{4}$ to $\mathrm{MnO}$ leading to the higher temperature one. ${ }^{34}$ The pattern of $\gamma-\mathrm{MnO}_{2}$ with the location of peaks at $305{ }^{\circ} \mathrm{C}$ and $403{ }^{\circ} \mathrm{C}$ exhibited a certain similarity with that of $\beta-\mathrm{MnO}_{2}$, and shows that the same reduction processes occurred as for $\beta-\mathrm{MnO}_{2}$. In contrast, $\alpha-\mathrm{MnO}_{2}$ exhibited two reduction peaks at $292{ }^{\circ} \mathrm{C}$ and $319{ }^{\circ} \mathrm{C}$. Similarly, $\delta-\mathrm{MnO}_{2}$ also showed two overlapping reduction peaks located at $269^{\circ} \mathrm{C}$ and $285{ }^{\circ} \mathrm{C}$. However, the ratio of the lower temperature peak to the higher temperature peak was about $1: 1$, which may indicate the existence of a different reduction route, that is $\mathrm{MnO}_{2}$ to $\mathrm{Mn}_{2} \mathrm{O}_{3}$ and then to $\mathrm{MnO}$. Nevertheless, it is clear from these results that the reduction capacity sequence should be $\delta$ - > $\alpha^{-}>\gamma^{-} \approx \beta-$, which is consistent with the previous report. ${ }^{30}$

Table 2 The $\mathrm{K}^{+}$content determined by ICP-OES and the XPS data for the $\alpha-, \beta-, \gamma$ - and $\delta-\mathrm{MnO}_{2}$ samples

\begin{tabular}{|c|c|c|c|c|c|c|c|}
\hline Samples & $\begin{array}{l}\mathbf{K}^{+} \\
\text {content } \\
{[\mathrm{wt} \%]}\end{array}$ & \multicolumn{2}{|c|}{ Binding energy $[\mathrm{eV}]$} & $\frac{\text { Molecular ratio }}{\mathrm{Mn}^{4+} / \mathrm{Mn}^{3+}}$ & \multicolumn{2}{|c|}{ Binding energy $[\mathrm{eV}]$} & $\frac{\text { Molecular ratio }}{\mathrm{O}_{\text {latt }} / \mathrm{O}_{\text {ads }}}$ \\
\hline$\alpha-\mathrm{MnO}_{2}$ & 7.1 & 642.6 & 641.8 & 5.6 & 529.7 & 531.3 & 4.1 \\
\hline$\beta-\mathrm{MnO}_{2}$ & 0 & 642.2 & 641.5 & 4.2 & 529.3 & 530.8 & 2.4 \\
\hline$\gamma-\mathrm{MnO}_{2}$ & 0 & 642.6 & 641.8 & 4.0 & 529.7 & 531.3 & 2.8 \\
\hline$\delta-\mathrm{MnO}_{2}$ & 6.4 & 642.5 & 641.8 & 8.3 & 529.6 & 531.3 & 5.5 \\
\hline
\end{tabular}




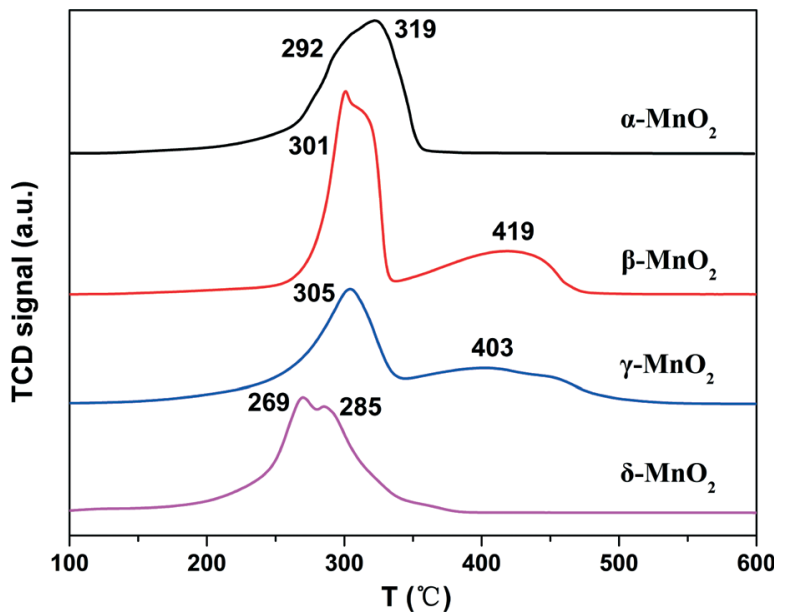

Fig. $6 \mathrm{H}_{2}$-TPR profiles of the $\alpha-, \beta-, \gamma-$ and $\delta-\mathrm{MnO}_{2}$ samples.

The reducibility tested by $\mathrm{H}_{2}$-TPR could reflect the oxygen mobility in the samples: since $\delta-\mathrm{MnO}_{2}$ shows the reduction peak at the lowest temperature, it was proven to possess the most mobile oxygen species both at the surface and in the bulk among the four catalysts. Consequently, the high oxygen mobility causes more oxygen to be adsorbed and further excited to active oxygen, which would then be involved in the reaction.

\subsection{XPS analysis}

To identify the states of the surface Mn and $\mathrm{O}$ elements and check our deduction from the $\mathrm{H}_{2}$-TPR experiment, XPS spectra were next measured. Fig. 7 a shows the Mn $2 p_{3 / 2}$ spectra of the series of catalysts. The peaks at 642.6 and $641.8 \mathrm{eV}$ could be attributed to the surface $\mathrm{Mn}^{4+}$ and $\mathrm{Mn}^{3+}$, respectively. ${ }^{36,37}$ The $\mathrm{Mn} 2 \mathrm{p}_{3 / 2}$ peak of $\beta-\mathrm{MnO}_{2}$ exhibited a certain shift of about $0.4 \mathrm{eV}$ to a lower binding energy, (ESI, $\dagger$ Fig. S4). This shift could be regarded as a system shift because it also emerged at the $\mathrm{O} 1 \mathrm{~s}$ peak (Fig. 7b). Thus, after the spectra were deconvoluted, the peaks of both $\mathrm{Mn}^{4+}$ and $\mathrm{Mn}^{3+}$ in $\beta-\mathrm{MnO}_{2}$ shifted to lower binding energies by about $0.4 \mathrm{eV}$. A quantitative analysis on the $\mathrm{Mn} 2 \mathrm{p}_{3 / 2}$ spectra was performed and the surface element molar ratios of $\mathrm{Mn}^{4+} / \mathrm{Mn}^{3+}$ are summarized in Table 2. Apparently, the surface $\mathrm{Mn}^{4+} / \mathrm{Mn}^{3+}$ molar ratios of the catalysts were distinct in $\mathrm{MnO}_{2}$ with different crystal structures. The $\delta-\mathrm{MnO}_{2}$ sample presented the highest $\mathrm{Mn}^{4+} / \mathrm{Mn}^{3+}$ molar ratio (8.3). The sequence of surface $\mathrm{Mn}^{4+}$ percentage followed the order $\delta->\alpha->\gamma^{-} \approx \beta-$

The XPS spectra of $\mathrm{O} 1 \mathrm{~s}$ are shown in Fig. 7b. The asymmetrical $\mathrm{O}$ 1s spectra could be deconvoluted to two peaks. The main species at a binding energy of $529.7 \mathrm{eV}$ was assigned to the lattice oxygen $\left(\mathrm{O}^{2-}\right)$ (denoted as $\left.\mathrm{O}_{\text {latt }}\right){ }^{37-39}$ and the signal at a binding energy of 531.3 corresponded to the surface adsorbed oxygen with low coordination (denoted as $\left.\mathrm{O}_{\text {ads }}\right)^{37,40}$ such as $\mathrm{O}_{2}{ }^{2-}$ or $\mathrm{O}^{-}$belonging to defect-oxide or hydroxyl-like groups. Different from the other samples, the $\mathrm{O}$ 1s peaks of $\beta-\mathrm{MnO}_{2}$ are shifted towards lower binding energies by about $0.4 \mathrm{eV}$, consistent with previous studies ${ }^{30,41,42}$ and the results of the Mn $2 \mathrm{p}$ spectra. In view of the system shift by $0.4 \mathrm{eV}$ on the spectra of $\beta-\mathrm{MnO}_{2}$, the binding energy locations of both $\mathrm{O}_{\text {ads }}$ and $\mathrm{O}_{\text {latt }}$ in the $\beta$ - sample are also disposed with a shift of about $0.4 \mathrm{eV}$ when the deconvolution is carried out. The surface element molar ratios $\mathrm{O}_{\text {latt }} / \mathrm{O}_{\text {ads }}$ were calculated and summarized in Table 2. They followed the sequence $\delta-\mathrm{MnO}_{2}(5.5)>\alpha-\mathrm{MnO}_{2}$ (4.1) $>\gamma-\mathrm{MnO}_{2}(2.8)>$ $\beta-\mathrm{MnO}_{2}$ (2.4). Generally, oxidation reactions such as $\mathrm{CO}$ and NO oxidation on $\mathrm{MnO}_{x}$ catalysts follow the Mars-van Krevelen mechanism, ${ }^{4,44}$ implying that the lattice oxygen concentration could dominate the activity during the reaction. ${ }^{45}$ Lee et al. $^{44}$ observed that $\mathrm{MnO}_{2}$ with more lattice oxygen was more active than $\mathrm{Mn}_{2} \mathrm{O}_{3}$ for the oxidation of NO to $\mathrm{NO}_{2}$. Tang et $a .^{26}$ have observed that the richer lattice oxygen in $\mathrm{Mn}-\mathrm{Ce}$ composite catalysts were advantageous for the
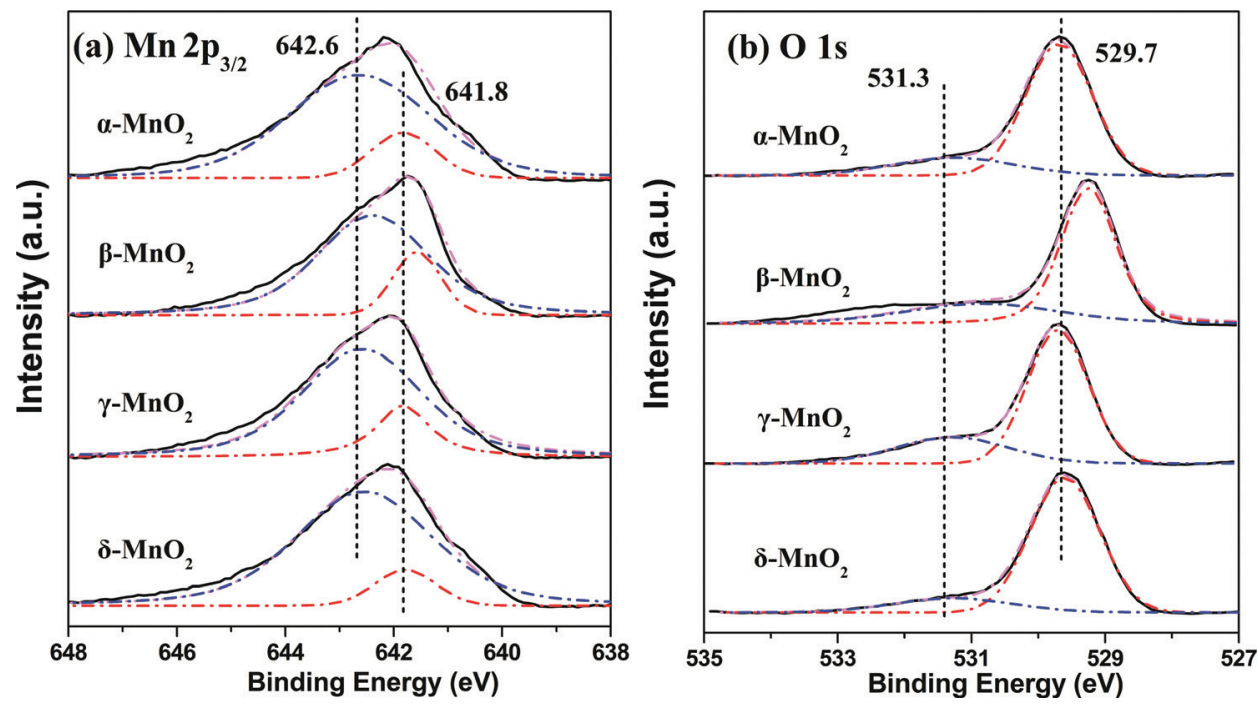

Fig. 7 XPS spectra of $\alpha-, \beta-, \gamma-$ and $\delta-M_{n} O_{2}$ samples: (a) $M n 2 p_{3 / 2}$ and (b) $O 1$ s. 
HCHO oxidation. In this study, the surface molar ratios $\mathrm{O}_{\text {latt }} / \mathrm{O}_{\mathrm{ads}}$ followed the order of the catalytic activities for HCHO oxidation among the four types of $\mathrm{MnO}_{2}$ catalyst, indicating that the activity is also closely related to the surface concentrations of $\mathrm{O}_{\text {latt }}$ species. Abundant lattice oxygen, such as that on $\delta-\mathrm{MnO}_{2}$, would lead to the excellent activity of $\mathrm{MnO}_{2}$ catalysts for $\mathrm{HCHO}$ oxidation. However, this conclusion is just deduced from the XPS data, and to our knowledge, no previous report directly demonstrates the function of lattice oxygen in $\mathrm{MnO}_{2}$ for $\mathrm{HCHO}$ catalytic oxidation. Furthermore, one recent study has claimed that the adsorbed oxygen species might play an important role in the total oxidation of toluene over $\mathrm{MnO}_{2}$ catalysts. ${ }^{46}$ Thus, the function of lattice oxygen needs to be verified by solid experimental data.

\subsection{Lattice oxygen test}

To confirm the role of lattice oxygen species on $\mathrm{MnO}_{2}$ in this reaction, $\delta-\mathrm{MnO}_{2}$ was next tested in the absence of oxygen in reaction gases. The details about the pretreatment of catalyst are given in the experimental section. Fig. 8 shows the concentration of both $\mathrm{HCHO}$ and $\mathrm{CO}_{2}$ as a function of time in the lattice oxygen test. After introducing $\mathrm{HCHO}$ into the reactor, $\mathrm{CO}_{2}$ concentration first rapidly increased to a maximum and then descended gradually to a low level. HCHO was detected in outlet gas after about $20 \mathrm{~min}$ and then its concentration slowly increased to a high level. It is noted that the $\mathrm{CO}_{2}$ concentration generated in the $75{ }^{\circ} \mathrm{C}$ test was much higher than that in the $50{ }^{\circ} \mathrm{C}$ test, showing that the active oxygen species in $\delta-\mathrm{MnO}_{2}$ was much more active at $75{ }^{\circ} \mathrm{C}$

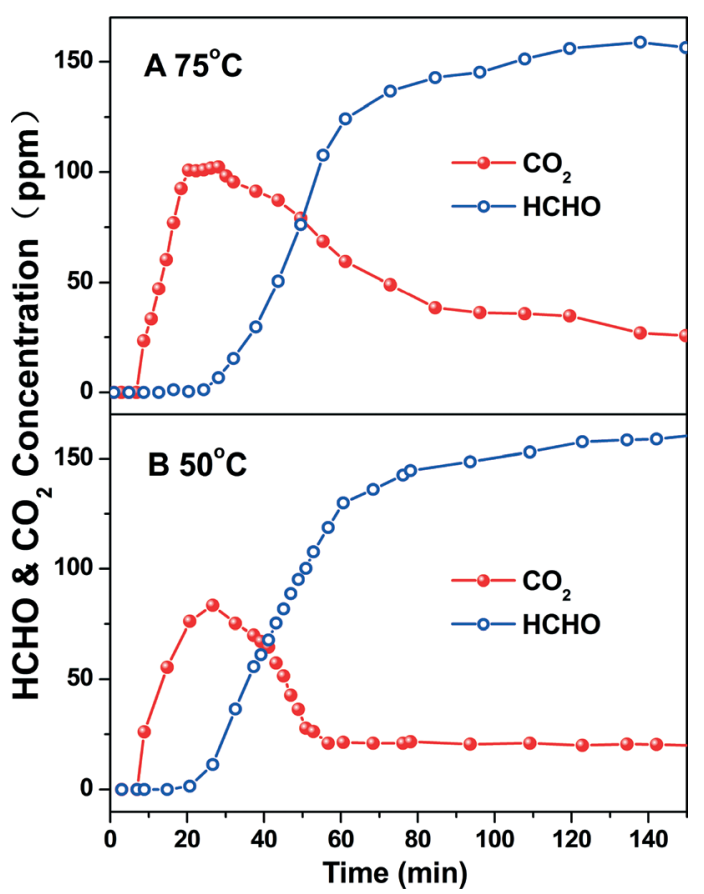

Fig. 8 Concentration variations of $\mathrm{HCHO}$ and $\mathrm{CO}_{2}$ with reaction time in the lattice oxygen test. than $50{ }^{\circ} \mathrm{C}$. The ratio of consumption of oxygen to total oxygen in the $\delta-\mathrm{MnO}_{2}$ catalyst was stoichiometrically calculated based on the amount of $\mathrm{CO}_{2}$ production. It is shown that $1.78 \%$ and $3.87 \%$ of the oxygen species were consumed during the $120 \mathrm{~min}$ reaction at $50{ }^{\circ} \mathrm{C}$ and $75{ }^{\circ} \mathrm{C}$, respectively. After being purged by pure $\mathrm{N}_{2}$ for $30 \mathrm{~min}$ at $150{ }^{\circ} \mathrm{C}$, there would be exclusively surface adsorbed oxygen and lattice oxygen species left on the pretreated catalyst surface. However, as shown in Fig. 6, no peak corresponding to surface adsorbed oxygen species was observed in the $\mathrm{H}_{2}$-TPR profile, indicating that the amount of surface adsorbed oxygen species should be at a considerably low level. As for the quantitative analysis, such a large amount of consumed oxygen during the reaction should mostly come from the lattice oxygen. Therefore, the high HCHO conversion rates in both tests would be attributed to the activated abounding surface lattice oxygen. The results confirmed that the lattice oxygen species were responsible for the total oxidation of $\mathrm{HCHO}$ over $\mathrm{MnO}_{2}$ catalysts.

Interestingly, the longer lasting production of $\mathrm{CO}_{2}$ in the $75^{\circ} \mathrm{C}$ test, especially the gradual reduction in the production rate from 60 minutes to 100 minutes, indicates that there might be lattice oxygen mobility from the bulk to the surface. After the surface lattice oxygen is partly consumed, the subsurface oxygen, even the more inner ones, gradually shift to the surface to participate in the oxidation reaction. As the mobility becomes lower upon moving from surface to bulk, the rate of supplementary oxygen species gradually decreases, thus leading to the drop in $\mathrm{CO}_{2}$ production.

\subsection{HCHO-TPD}

To investigate the adsorption/desorption properties of $\mathrm{HCHO}$ on the surfaces of the $\mathrm{MnO}_{2}$ catalysts, HCHO-TPD was next

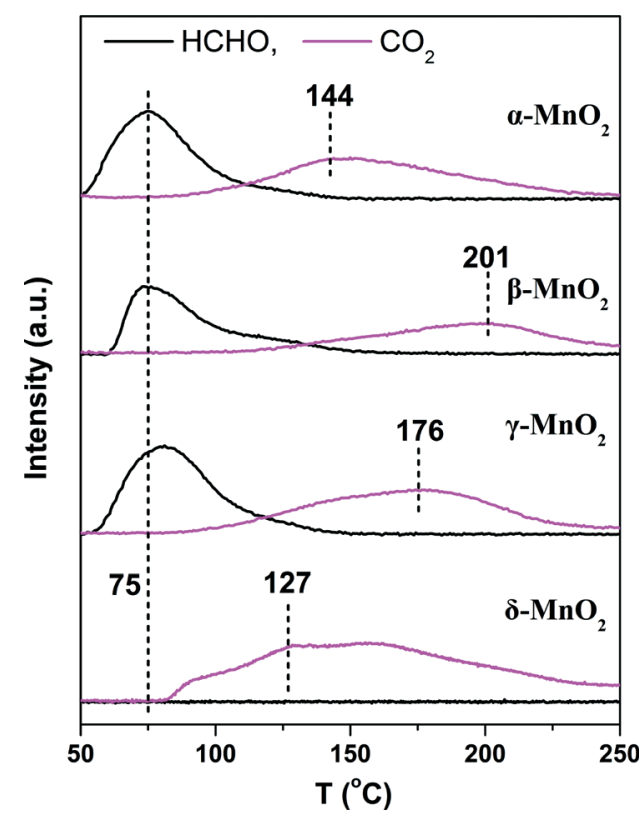

Fig. $9 \mathrm{HCHO}-\mathrm{TPD}$ results of $\alpha-, \beta-, \gamma-$ and $\delta-\mathrm{MnO}_{2}$ catalysts. 
carried out. As shown in Fig. 9, the HCHO molecules were desorbed at around $50{ }^{\circ} \mathrm{C}$ and then reached their peaks at about $75{ }^{\circ} \mathrm{C}$ on the $\alpha-, \beta$-, and $\gamma-\mathrm{MnO}_{2}$ catalysts, while no $\mathrm{HCHO}$ desorption was observed on $\delta-\mathrm{MnO}_{2} \cdot \mathrm{CO}_{2}$ was detected on all samples during the HCHO-TPD starting at around $75{ }^{\circ} \mathrm{C}$, with peaks at $144{ }^{\circ} \mathrm{C}, 201{ }^{\circ} \mathrm{C}, 176{ }^{\circ} \mathrm{C}$ and $127{ }^{\circ} \mathrm{C}$, for the $\alpha-\delta-\mathrm{MnO}_{2}$ catalysts respectively. $\mathrm{CO}_{2}$-TPD experiments were also performed, and the results (ESI, $\dagger$ Fig. S5) show that the $\mathrm{CO}_{2}$ desorption temperatures for the four catalysts were all lower than $100{ }^{\circ} \mathrm{C}$, confirming that the $\mathrm{CO}_{2}$ in the HCHO-TPD experiments was mainly produced by the oxidation of some adsorbed HCHO or intermediates. ${ }^{47}$ Therefore, $\mathrm{HCHO}$ desorption and $\mathrm{CO}_{2}$ production should be closely dependent on the activity of the surface lattice oxygen species. When the lattice oxygen species are highly active at low temperature, such as on the $\delta-\mathrm{MnO}_{2}$ catalyst, all adsorbed $\mathrm{HCHO}$ would be oxidized into $\mathrm{CO}_{2}$ without desorption during the ramping temperature.

\section{Conclusions}

In summary, we prepared $\alpha-, \beta-, \gamma$ - and $\delta$-type $\mathrm{MnO}_{2}$ catalysts and observed their very different activities for the catalytic oxidation of HCHO. This enormous difference in activities originates from their different physical properties at the surface, $\mathrm{K}^{+}$content, tunnel structures, the mobility of oxygen species, lattice oxygen abundances and also HCHO adsorption/desorption properties. However, the tunnel structures and lattice oxygen mobility and abundances might play a more important role in the $\mathrm{HCHO}$ oxidation reaction. $\delta-\mathrm{MnO}_{2}$ has a special 2D layer tunnel structure and also contains the most active oxygen species and the highest amount of lattice oxygen species on the catalyst surface, therefore, presenting the highest activity of the four types of $\mathrm{MnO}_{2}$ catalyst. Moreover, due to the high catalytic performance and facile preparation process, $\delta-\mathrm{MnO}_{2}$ may potentially be used as a support in applications of supported catalysts.

\section{Acknowledgements}

This work was financially supported by the National Natural Science Foundation of China (21422706) and the Program of the Ministry of Science and Technology of China (2012AA062702).

\section{Notes and references}

1 Y. Sekine, Atmos. Environ., 2002, 36, 5543.

2 J. Pei and J. Zhang, HVAC\&R Research, 2011, 17, 476.

3 R. Maddalena, M. Russell, D. Sullivan and M. Apte, Environ. Sci. Technol., 2009, 43, 5626.

4 J. Yang, Y. Qin, Y. Zeng and X. Ding, Food Sci., 2014, 35, 294.

5 J. Shie, C. Lee, C. Chiou, C. Chang, C. Chang and C. Chang, J. Hazard. Mater., 2008, 155, 164.

6 T. Noguchi and A. Fujishima, Environ. Sci. Technol., 1998, 32, 3831.

7 M. Chang and C. Lee, Environ. Sci. Technol., 1995, 29, 181.
8 C. Ma, X. Li and T. Zhu, Carbon, 2011, 49, 2873.

9 C. Zhang, F. Liu, Y. Zhai, H. Ariga, N. Yi, Y. Liu, K. Asakura, M. Flytzani-Stephanopoulos and H. He, Angew. Chem., Int. Ed., 2012, 51, 9628.

10 B. Bai, H. Arandiyan and J. Li, Appl. Catal., B, 2013, 142, 677.

11 C. Zhang, H. He and K. Tanaka, Appl. Catal., B, 2006, 65, 37.

12 T. Quiroz, S. Royer, J. Bellat, J. Giraudon and J. Lamonier, ChemSusChem, 2013, 6, 578.

13 C. Zhang and H. He, Catal. Today, 2007, 126, 345.

14 B. Liu, Y. Liu, C. Li, W. Hu, P. Jing, Q. Wang and J. Zhang, Appl. Catal., B, 2012, 127, 47.

15 B. Liu, C. Li, Y. Zhang, Y. Liu, W. Hu, Q. Wang, L. Han and J. Zhang, Appl. Catal., B, 2012, 111, 467.

16 X. Tang, J. Chen, X. Huang, Y. Xu and W. Shen, Appl. Catal., $B, 2008,81,115$.

17 H. Huang and D. Leung, ACS Catal., 2011, 1, 348.

18 C. Zhang, Y. Li, Y. Wang and H. He, Environ. Sci. Technol, 2014, 48, 5816.

19 C. Shi, B. Chen, X. Li, M. Crocker, Y. Wang and A. Zhu, Chem. Eng. J., 2012, 200, 729.

20 Z. Qu, S. Shen, D. Chen and Y. Wang, J. Mol. Catal. A: Chem., 2012, 356, 171.

21 Z. Huang, X. Gu, Q. Cao, P. Hu, J. Hao, J. Li and X. Tang, Angew. Chem., Int. Ed., 2012, 51, 4198.

22 Q. Wang, W. Jia, B. Liu, W. Zhao, C. Li, J. Zhang and G. Xu, Chem. - Asian J., 2012, 7, 2258.

23 L. Zhou, J. He, J. Zhang, Z. He, Y. Hu, C. Zhang and H. He, J. Phys. Chem. C, 2011, 115, 16873.

24 L. Ma, D. Wang, J. Li, B. Bai, L. Fu and Y. Li, Appl. Catal., B, 2014, 148, 36.

25 L. Nie, J. Yu, X. Li, B. Cheng, G. Liu and M. Jaroniec, Environ. Sci. Technol., 2013, 47, 2777.

26 X. Tang, Y. Li, X. Huang, Y. Xu, H. Zhu, J. Wang and W. Shen, Appl. Catal., B, 2006, 62, 265.

27 H. Chen, J. H. C. Zhang and H. He, J. Phys. Chem. C, 2007, 111, 18033.

28 T. Chen, H. Dou, X. Li, X. Tang, J. Li and J. Hao, Microporous Mesoporous Mater., 2009, 122, 270.

29 Y. Wang, A. Zhu, B. Chen, M. Crocker and C. Shi, Catal. Commun., 2013, 36, 52.

30 S. Liang, F. Bulgan, R. Zong and Y. Zhu, J. Phys. Chem. C, 2008, 112, 5307.

31 S. Turner and P. Buseck, Science, 1979, 203, 456.

32 Y. Chabre and J. Pannetier, Prog. Solid State Chem., 1995, 23, 1.

33 J. Post and D. Veblen, Am. Mineral., 1990, 75, 477.

34 J. Hou, L. Liu, Y. Li, M. Mao, H. Lv and X. Zhao, Environ. Sci. Technol., 2013, 47, 13730.

35 S. Devarajand and N. Munichandraiah, J. Phys. Chem. C, 2008, 112, 4406.

36 A. Wollner, F. Lang, H. Schmelz and H. Knozinger, Appl. Catal., A, 1993, 94, 181.

37 M. Toupin, T. Brousse and D. Belanger, Chem. Mater., 2004, 16, 3184.

38 S. Cai, D. Zhang, L. Zhang, L. Huang, H. Li, R. Gao, L. Shi and J. Zhang, Catal. Sci. Technol., 2014, 4, 93. 
39 B. Tan, K. Klabunde and P. Sherwood, J. Am. Chem. Soc., 1991, 113, 855.

40 X. Tang, J. Chen, Y. Li, Y. Li, Y. Xu and W. Shen, Chem. Eng. J., 2006, 118, 119.

41 C. Yu, G. Li, L. Wei, Q. Fan, Q. Shu and J. Yu, Catal. Today, 2014, 224, 154.

42 J. Li, C. Song and S. Liu, Acta Chim. Sin., 2012, 70, 2347.

43 R. Xu, X. Wang, D. Wang, K. Zhou and Y. Li, J. Catal.,
2006, 237, 426.

44 S. Lee, K. Park, S. Kim, D. Kwon and S. Hong, J. Air Waste Manage. Assoc., 2012, 62, 1085.

45 W. Song and E. Hensen, Catal. Sci. Technol., 2013, 3, 3020.

46 F. Wang, H. Dai, J. Deng, G. Bai, K. Ji and Y. Liu, Environ. Sci. Technol., 2012, 46, 4034.

47 G. Busca, J. Lamotte, J. Lavalley and V. Lorenzelli, J. Am. Chem. Soc., 1987, 109, 5197. 